\title{
Craniofacial Neuralgias
}

Corresponding author: Sheryl D. Katta-Charles, MD, BIM

Assistant Professor, Dept Physical Medicine and Rehabilitation

Indiana University School of Medicine

Rehabilitation Hospital of Indiana

4141 Shore Drive, Indianapolis, IN

Office: $317-329-2200$

Cell Phone: 630-806-9793

Fax: 317-329-2360

\begin{abstract}
While non-headache, non-oral craniofacial neuralgia is relatively rare in incidence and prevalence, the condition can result in debilitating pain. Understanding relevant anatomy of peripheral branches of nerves, natural history, clinical presentation, and management strategies will help the clinician in better diagnosis and treatment of craniofacial neuralgias. In this article we review nerves responsible for neuralgiform pain distinct from idiopathic trigeminal neuralgia that results in periorbital, periauricular and occipital pain. Periorbital neuralgia is mediated by infratrochlear, supratrochlear, supraorbital, lacrimal and infraorbital nerves. Periauricular neuralgia may involve the auriculotemporal nerve, the great auricular nerve, and the nervus intermedius. Occipital neuralgias can be transmitted by the greater occipital nerve, lesser occipital nerve and third occipital nerve. A wide range of treatment options exist, from modalities to surgery and the evidence behind each will be reviewed.
\end{abstract}

Keywords: Craniofacial neuralgia; glossopharyngeal neuralgia; trigeminal neuralgia; great auricular nerve; lesser occipital nerve; third occipital nerve; occipital neuralgia

This is the author's manuscript of the article published in final edited form as:

Katta-Charles, S. D. (2020). Craniofacial neuralgias. NeuroRehabilitation, 47(3), 299-314. https://doi.org/10.3233/NRE-208004 


\section{Introduction}

Craniofacial neuralgias are the result of abnormality in the neural components innervating the cutaneous head. The result is pain in the distribution of the nerve, characterized as shock-like. The pain can be momentary or continuous, moderate to severe in intensity, elicited by relatively mild or even nonpainful stimuli. While non-headache, non-dental craniofacial neuralgia is relatively rare in incidence and prevalence, craniofacial neuralgias can result in debilitating pain. Understanding relevant anatomy of peripheral branches of nerves, natural history, clinical presentation, and management strategies will help the clinician better treat the condition. Idiopathic trigeminal neuralgia is probably the most widely known neuralgiform disorder. In this article, we review some less well-known nerves that cause similar pain in specific distribution. We will review pain centered on periorbital, periauricular, posterior head regions including non-neuropathic differentials. It is important to note that in some countries, neuralgia is a term reserved for episodic neuropathic pains with nonpainful intervals, but in this article neuropathic pain and neuralgia will be used interchangeably.

\section{Anatomy}

The afferent nerves transmitting pain and sensation from the head and face are well-recognized. The largest cranial nerve, trigeminal nerve, serves almost the entire face, while distinctively sparing the angle of the mandible, through three branches and many subbranches. A portion of the external ear canal is innervated by auricular branch of the vagus nerve, cranial nerve X. Sensation in the throat is innervated by the glossopharyngeal nerve, cranial nerve IX, pain from which can radiate to the ear. ${ }^{3}$

The skin over the posterior head and neck is innervated by ventral and dorsal portions of C2-C4. C1 nerve root predominantly gives off motor nerves, except a small meningeal branch that provides sensation to the dura around foramen magnum. ${ }^{1}$ The dorsal ramus of $\mathrm{C} 2$ gives the greater occipital nerve, which provides sensation to the posterior head. The dorsal ramus of $\mathrm{C} 3$ produces the third occipital nerve, implicated in whiplash syndrome and also provides sensation to a portion of the posterior head. ${ }^{1}$ The ventral rami of $\mathrm{C} 2$ to $\mathrm{C} 4$ come together deep to the sternocleidomastoid (SCM) to form the cervical plexus, which gives off four sensory cutaneous nerves: the great auricular nerve (GAN), lesser occipital nerve, transverse 
cervical nerve and supraclavicular nerve. ${ }^{1}$ These nerves innervate the skin over the angle of the mandible, the anterior neck and back of the head and neck, the inferior part of the lateral aspect of the auricle and the lateral and anterior aspects of the neck. ${ }^{1}$

\section{Trigeminal Neuralgia}

Trigeminal neuralgia (TN) may be the most well-known cause of severe facial pain. Responsible for detecting pain and sensation from the face, the cell bodies of the sensory portion of the trigeminal nerve are located in the gasserian (semilunar) ganglion. ${ }^{3}$ The nerves make connections with second-order neurons in the subnucleus caudalis portion of the trigeminal nucleus. Impulses are then carried to the thalamus from where thalmocortical projections emerge. ${ }^{3}$ The subnucleus caudalis also receives input from other nerves, including cranial nerves IX and $\mathrm{X}$ as well as the upper cervical nerves, and the nucleus is implicated in the pathology of migraines and cervicogenic headaches. ${ }^{2}$

The ophthalmic division (V1) of the trigeminal nerve occupies the cavernous sinus and courses through the superior orbital fissure and transmits sensation from the forehead, conjunctiva and cornea, as well as the mucosa of the nose, frontal, sphenoid and ethmoid sinuses, and the lacrimal duct. ${ }^{3}$ The maxillary division (V2) also occupies the cavernous sinus but courses through the foramen rotundum carrying sensation from the skin of the midface, the mucosa of the anterior nasopharynx, the upper portion of the hard and soft palate, the gums of the upper jaw and the upper teeth. ${ }^{3}$ The sensory portion of the mandibular division (V3) carries sensation from the lower face, the mucosa of the lower jaw, floor of the mouth, lower teeth and gum and general sensation, but not taste, from the anterior two-thirds of the tongue. ${ }^{3}$

$\mathrm{TN}$ can occur due to idiopathic or secondary causes. Idiopathic TN is rare, affecting 4 to 13 people per $100,000 .{ }^{4}$ Known to be one of the worst known pain that humans can experience, idiopathic TN is understandably associated with depression in $36 \%$ of patients and disability in $45 \%$ of patients. ${ }^{5}$ Although the pathogenesis of idiopathic TN is not completely understood, the longstanding and widely accepted model implicates sustained or pulsatile microvascular compression of the trigeminal root by neurovascular structures, over time leading to focal demyelination of the nerve, resulting in neuropathic pain. That microvascular decompression regularly provides pain relief has been offered as proof of this model. 
Idiopathic TN primarily affects those in the age between 37 and $67 .^{7}$ Women are three times more likely to be affected than men. ${ }^{4}$

Idiopathic $\mathrm{TN}$ can have varying presentation. Typical $\mathrm{TN}$ is characterized by recurrent unilateral brief electric shock-like pains. The pain is usually abrupt in onset and termination and is limited to the distribution of one or more divisions of the trigeminal nerve. The pain may be triggered by innocuous stimuli. ${ }^{5}$ In addition to the shock-like pains, $15 \%$ of patients suffer from continuous pain of moderate intensity within the distribution of the affected nerve divisions. ${ }^{5}$ This presentation is referred to as atypical TN. Another atypical presentation of TN is tic douloureux, contraction of the muscles of the face on the affected side. In yet another kind, $17 \%$ of individuals can exhibit autonomic symptoms such as lacrimation or redness of the ipsilateral eye. ${ }^{5}$ On physical exam, numbness is absent in typical TN.

Causes of secondary TN include multiple sclerosis, space-occupying lesion, herpes zoster, and trauma. Clinical history and physical exam can be useful in localizing the lesion and narrowing the differential diagnosis. Other than facial numbness or pain, weakness in chewing may be reported in a proximal V3 lesion. Eye redness and tearing may be reported if debris in the eye caused keratitis. Those with secondary TN due to central etiology may have other symptoms such as hemiparesis contralateral to the facial symptoms, such as in the event of a brainstem stroke. In addition, to light touch and pin prick in trigeminal dermatomes corneal reflex, jaw jerk reflex can reveal a V1 and V3 lesions, respectively. In V3 lesions, a subtle jaw deviation to the side of the weakness may occur on mouth opening. This deviation may be subtle and may not persist on repetition. A cavernous sinus lesion would present with concomitant cranial nerve III and IV deficits, such as ophthalmoplegia, mydriasis, and proptosis.

Traumatic injuries such as motor vehicle accidents; or iatrogenic injuries during dental, facial, or neurosurgical procedures can produce traumatic craniofacial neuralgias. ${ }^{8-11}$ In these cases, physical exam would reveal tenderness on palpation of the corresponding nerve, intact sensation or hypoesthesia in the territory of the nerve and pain relief with a diagnostic block. Nerve block administration in the palpation 
landmark resulting in transient but complete pain relief can confirm the diagnosis. Further treatment may involve surgical release of an entrapped nerve.

\section{Periorbital Neuralgias}

Injury to the branches of the ophthalmic branch of the trigeminal nerve (V1) and maxillary nerve (V2) results in periorbital neuralgia. The frontal nerve is the largest branch of the ophthalmic nerve and itself branches into the supraorbital nerve $(\mathrm{SON})^{14}$ and supratrochlear nerves $(\mathrm{STN})^{12}$ after entering the orbit through the superior orbital fissure. Both terminal branches then circle the orbital cavity and run rostral to supply sensory innervation to the forehead, sometimes in overlapping territories. The ophthalmic nerve also gives off lacrimal nerve and the infratrochlear nerve via the nasociliary branch, which also contribute to periorbital neuralgia. The afferent portion of the blink reflex is supplied by the nasociliary branch of V1 and may be affected depending on the location of injury of V1.

\section{Supratrochlear neuralgia}

The STN emerges from the medial one-third portion of the orbit. ${ }^{12}$ The STN serves the skin of the lower forehead close to the midline, the eyebrow and the superointernal angle of the orbit while the SON serves the remainder of the forehead. ${ }^{14}$ The STN passes under the corrugator and frontalis muscles close to the bone and intramuscular entrapment due to frowning, forced eye closure is possible. ${ }^{14}$

\section{Supraorbital neuralgia}

The SON innervates the majority of the forehead. The SON emerges through the supraorbital notch, a landmark for palpation and nerve blocks. ${ }^{15}$ The SON can be compressed by external headwear such as tight caps. Such mechanisms of entrapment may result in bilateral involvement and synchronous pain crossing the midline. Unilateral supraorbital neuralgia accounts for $0.5 \%$ of unilateral headache. ${ }^{16}$

An important differential diagnosis to supraorbital neuralgia is giant cell arteritis (GCA). A type of large vessel vasculitis, GCA starts insidiously over weeks to months and symptoms of headache, scalp 
tenderness, jaw claudication, fever, fatigue, weight loss and visual changes are not uncommon. The headache is constant, located in temporal region and severe in quality. The superior temporal artery is almost always involved. ${ }^{13}$ The patient may deny headache and may call the symptom "head pain" instead. Not always does GCA present with temporal artery tenderness, prominence and hardness. American College of Rheumatology criteria include presence of 3 or more of the following: age older than 50 years of age, new onset localized headache, temporal artery tenderness or decreased pulsation, erythrocyte sedimentation rate $(\mathrm{ESR})>50 \mathrm{~mm} / \mathrm{h}$, and abnormal temporal artery biopsy. ${ }^{17}$

\section{Lacrimal neuralgia}

The external canthus, the lateral upper eyelid as well as the lacrimal gland are supplied by the lacrimal nerve. Hypoesthesia and neuralgia involving the lateral upper eyelid and external canthus should prompt the diagnosis of lacrimal neuralgia. In addition to neuralgic symptoms, exacerbations of lacrimal neuralgia may produce tearing and itchiness of the eye. ${ }^{18}$

\section{Infratrochlear neuralgia}

The infratrochlear nerve innervates the internal angle of the orbit and medial upper eyelid, upper bridge of the nose and/or lacrimal caruncle. The infratrochlear nerve can be palpated and nerve block can be administered in the internal angle of the orbit above the internal canthus. ${ }^{13}$

\section{Infraorbital neuralgia}

Neuralgic symptoms in the area of the lower eyelid, side of the nose, nasal septum, anterior cheek and upper lip is suspicious for infraorbital neuralgia. The infraorbital nerve is a branch of the maxillary branch of the trigeminal nerve (V2). It travels through the foramen rotundum, the pterygopalatine fossa, through the orbit and exits the infraorbital foramen to innervate the mid-face via four branches, the superior labial, internal nasal, external nasal and inferior palpebral nerves. ${ }^{19}$ The nerve is located at the mid-pupillary line approximately $7 \mathrm{~mm}$ below the infraorbital rim. ${ }^{19}$ The infraorbital nerve can suffer 
neuropraxia from tight nasal masks, during certain facial procedures (such as cleft lip repair) or in an orbital floor fracture.

In one case series ${ }^{20}$ nine patients with orbital floor fractures that did not entrap extraocular muscles, cause enopthalmos, diplopia or loss of ocular movements and thereby did not meet criteria for surgical repair, yet entrapped the infraorbital nerve, resulting in significant infraorbital neuralgia. These patients suffered from chronic pain and depression, which resolved after decompression of the infraorbital canal. ${ }^{21}$ Blockade of the intraorbital nerve can be achieved intraorally along the inner surface of the lip; or transcutaneously lateral to the infraorbital foremen. ${ }^{22}$

An important differential diagnosis to craniofacial neuralgias is persistent idiopathic facial pain (PIFP). Previously referred to as atypical facial pain, PIFP is described as "persistent facial and/or oral pain, with varying presentations" and can recur daily for more than 2 hours each day, over 3 months or longer, in the absence of clinical neurological deficit. ${ }^{23}$ The exact pathophysiology underlying PIFP is unclear and is thought to be a disproportionate pain reaction to a mild injury. Neuropathic pain usually begins with or worsens after a minor surgical or invasive dental procedure. The pain is usually reported as spreading in a non-dermatomal manner and aggravated by emotional stress. Many with PIFP first carry a diagnosis of depression. ${ }^{24}$ PIFP is reminiscent of complex regional pain syndrome (CRPS) type 1 (previously known as reflex sympathetic dystrophy, while TN resembles CRPS type 2 (previously causalgia).

\section{Periauricular Neuralgias}

The auricle derives its sensory innervation from three nerves. The auriculotemporal nerve innervates the tragus, crux and ascending helix. The great auricular branch of the superficial cervical nerve innervates the ear lobe, posterior parts of the helix and the antihelix. The nervus intermedius formed by the vagus nerve anastomosed with the facial nerve supplies the concha, known as the Ramsay Hunt's zone. The various innervations intersect and are not easily differentiated. Palpation of the auricle between 
fingers can help find nerve filaments. Portions that are sensitive to palpation may benefit from anesthetic blockade. $^{25}$

\section{Auriculotemporal Neuralgia}

The auriculotemporal nerve (ATN) is a branch of the mandibular nerve (V3) and gives off five branches: the anterior auricular, articular, parotid, superficial temporal and branches to the external auditory meatus. ${ }^{26}$ Of relevance to craniofacial neuralgias are all the subbranches except the parotid branch, which contains parasympathetic nerve fibers innervating the parotid gland and its vasculature. When ATN is compressed or stretched, auriculotemporal neuralgia is felt in the temporal scalp, temporomandibular joint, parotid and auricular regions. It is characterized as brief paroxysms of pain radiating between the posterior scalp to the ipsilateral eye or nose in a linear or zigzag manner, lasting less than 10 seconds. ${ }^{27} \mathrm{TMJ}$ arthritis is an important differential diagnosis for chronic pre-auricular pain. Due to its proximity to the temporomandibular joint (TMJ), complications of arthroscopy represented $60 \%$ of ATN injuries with a complication rate of of 1 in $670 \mathrm{TMJ}$ arthroscopy cases. ${ }^{28}$

\section{Great Auricular Neuralgia}

The great auricular nerve (GAN) originates from the $\mathrm{C} 2-\mathrm{C} 3$ nerve roots. The nerve emerges out of the midpoint of the SCM, wraps around the belly of the muscle, ascends and splits into an anterior and a posterior branch. The anterior branch innervates the skin over the pre-auricular region, parotid, and mandibular angle. The posterior branch innervates the skin of the posteroinferior pinna.

Damage to the GAN is uncommon but case series have reported occurrence after trauma to the neck or procedures such as salivary glands resection, cervical lymph node dissection, pacemaker placement, carotid endarterectomies and rhytidectomy (face-lift). ${ }^{29-31}$ The pain resulting from GAN injury is most often described as paroxysmal stabbing in nature, provoked by turning the head, touching the neck, neck position during sleep and jaw movement. The pain is usually located along the lateral neck, jaw and outer ear. Redness and flushing of the ear ipsilateral to pain during an attack has been reported. Such a

presentation is consistent with what was previously referred to as "red ear syndrome." Many patients have 
gradual improvement in discomfort during the first year but a small number can have discomfort lasting years. ${ }^{31}$

Diagnosis is based on history and physical exam. Positive Tinel's maneuver over McKinney's point located one-third the distance from the external auditory canal to the clavicular origin of the SCM along the posterior border of the SCM, can be indicative of a GAN pathology. Those with systemic symptoms or history of cancer warrant imaging of the soft tissues of the neck. An MRI or CT of the neck with contrast would cover ear or jaw pathology, which can also present with referred pain to the neck. Nerve conduction study can help confirm the diagnosis.

High resolution ultrasound may be able to collect images of the superficial GAN and defects such as GAN neuroma. ${ }^{32}$ Ultrasound can also help in performing diagnostic blocks. GAN blocks can be dramatically effective in relieving pain. ${ }^{33}$ Ultrasound-guided serial blocks have been reported to be welltolerated. GAN stimulator is another option. Rarely, GAN resection may be necessary as in one case involving GAN lymphoma. ${ }^{31}$

\section{Nervus intermedius neuralgia}

Located in an intermediate position between the facial nerve and vestibular nerves, ${ }^{34}$ the nervus intermedius, also known as the geniculate nerve, contains the sensory and parasympathetic components of the facial nerve. The condition itself is referred to also as geniculate ganglionitis or Ramsay Hunt Syndrome when caused by herpes zoster. ${ }^{34}$ A rare disorder, fewer than 150 cases have been reported in the literature by any name. The nervus intermedius carries general sensation from the external auditory meatus, from the mucus membranes of the nasopharynx, and nose and special sensory information (taste) from the anterior two-thirds of the tongue, floor of the mouth and the soft palate. ${ }^{3}$ The general sensory information from the nasopharynx and palate is carried along the greater petrosal nerves while the chorda tympani carries taste. ${ }^{3}$

Nervus intermedius neuralgia pain is experienced deep in the ear, sometimes radiating to the parieto-occipital region. Cold, noise or swallowing may trigger the pain, but there is almost always a 
trigger zone in posterior wall of the auditory canal. ${ }^{23,36}$ Similar to idiopathic $\mathrm{TN}$, one cause of nervus intermedius is compression by vascular structures. ${ }^{34}$ When conservative medical treatment fails, surgical treatment in the form of transection of the nervus intermedius or microvascular decompression may be options. $^{34}$

\section{Glossopharyngeal neuralgia}

Cranial nerve IX, the glossopharyngeal nerve provides sensation to the pharynx, tonsil, soft palate and posterior tongue base. ${ }^{3}$ Glossopharyngeal neuralgia can radiate to the inner ear, angle of the mandible ${ }^{35}$ and is an important consideration in diagnosing and treating periauricular neuralgia. The pain of glossopharyngeal neuralgia is exacerbated by talking, yawning, coughing or swallowing. ${ }^{35}$ Pain comes in episodes and may disappear for days. Patients may lose weight due to pain with chewing and swallowing. They may also experience syncope. ${ }^{35}$ Physical exam may show no deficits, or dysesthesia/hyperalgesia and absent cough or gag reflex.

Jugular foramen syndrome characterized by paresis of the glossopharngyeal, vagal and accessory nerves may present as glossopharyngeal neuralgia. ${ }^{39}$ Jugular foramen syndrome may occur due to congenital primary cholesteatoma, vascular anomalies, vasculitides, infecions including herpes and varicella zoster, due to mass effect from parapharyngeal abscesses or neoplasms or due to traumatic posterior skull base fractures.

Diagnostic blocks of the glossopharyngeal nerve can be tricky. In using the transcutaneous technique, extreme care must be taken to avoid the internal jugular vein and the carotid artery. ${ }^{36}$ Concomitant block of the recurrent laryngeal nerve may be unavoidable. Therefore, bilateral blockades are not recommended in order to avoid complete vocal cord paresis. Surgical treatment of neuralgia may depend on the etiology. In cases of trauma, decompression of the glossopharyngeal nerve may be pursued. ${ }^{40}$ 


\section{Occipital Neuralgia}

Neuralgia in the posterior head is collectively referred to as occipital neuralgia. The posterior scalp up to the vertex is innervated by the greater occipital nerve (GON), the lesser occipital nerve (LON) and the third occipital nerve (TON).$^{44}$ Occipital neuralgia is characterized by sharp, electrical, paroxysmal pain originating from the occiput and extending along the posterior scalp in the distribution of GON, LON and/or TON. ${ }^{41}$ Occipital neuralgia can be caused by compression of the nerves by vascular, neoplastic or osteogenic structures. ${ }^{41}$ Another cause is entrapment of the occipital cutaneous nerves at the points where they pierce the muscles of the neck. ${ }^{42}$ The most common trigger of occipital neuralgia is the compression of GON and LON, affecting 3 out of every 100,000 people. ${ }^{43}$ GON has a higher frequency of involvement in the pain symptom than LON (90\% vs $10 \%){ }^{44}$

\section{Greater Occipital Neuralgia}

The GON arises from the dorsal ramus of $\mathrm{C} 2$ and, to a lesser extent, $\mathrm{C} 3$. The nerve runs around the lower border of the obliquus capitis inferior (OCI), crosses the suboccipital triangle, runs rostrally along the rectus capitis posterior major, receives a communicating branch from the TON, then pierces the semispinalis capitis (SSC), tendon of the trapezius along with the deep cervical fascia just below the superior nuchal ridge along with the occipital artery and supplies the medial portion of the posterior scalp to the vertex. ${ }^{45}$

The GON can be compressed or entrapped at various points along its course. First, it can be entrapped, where it emerges from the $\mathrm{C} 2$ dorsal ramus, when the head is rotated and an external biomechanical force crushes the GON between the atlantal facet and the axial lamina. ${ }^{47,48}$ Other points of GON vulnerability include its courses between the OCI and SSC muscles; at the point where it pierces the semispinalis muscle; while exiting the tendinous aponeurosis of the trapezius and lastly by the occipital artery which courses adjacent to it. ${ }^{48}$ In patients with ventriculoperitoneal shunts, compression of GON by the shunt catheter has been reported. ${ }^{46}$

The GON can be palpated $4 \mathrm{~cm}$ lateral to the external occipital protruberence (EOP). ${ }^{49}$ The GON is $3.5 \mathrm{~mm}$ wide and branches into medial and lateral branches on average $0.5 \mathrm{~cm}$ superior to the EOP. ${ }^{49} \mathrm{In}$ 
addition to neuralgia, GON entrapment can cause occipital and cervicogenic headaches. Sometimes the GAN can put forth a mastoid branch which runs close to the GON, about $9 \mathrm{~cm}$ lateral to the EOP. ${ }^{49}$

\section{Lesser Occipital Neuralgia}

The $\mathrm{LON}$ arises from the ventral ramus of $\mathrm{C} 2$ and $\mathrm{C} 3$, passes superiorly along the posterior border of the sternocleidomastoid (SCM) muscle innervating the lateral portion of the posterior scalp and the cranial surface of the pinna of the ear. ${ }^{49}$ The LON can be palpated within $10 \mathrm{~mm}$ of the mastoid prominence along the posterior border of the SCM, and on average $7 \mathrm{~cm}$ lateral to the external occipital protuberance (EOP). ${ }^{49}$ Rarely the nerve pierces the SCM and ascends on top of the muscle belly. ${ }^{50}$ The LON branches into a medial and lateral component midpoint between a horizontal line drawn through the EOP and the intermastoid line. ${ }^{50}$ The $\mathrm{C} 2$ ventral ramus is susceptible to stretch by the inferior oblique muscle (IOM), compression where it crosses the atlantoaxial junction or by the vertebral artery. ${ }^{51}$

\section{Third occipital neuralgia}

The TON is a delicate structure with a mean diameter of $1.3 \mathrm{~mm}$ at its widest and is located approximately $3 \mathrm{~mm}$ lateral to the EOP. ${ }^{49}$ Small branches cross the midline and communicate with the contralateral TON inferior to the EOP very often. The TON also puts forth a branch to the GON. The TON innervates a small area of skin in the occipital region and C2-C3 facet joint. Due to their proximity, the same mechanism that damages one TON may very likely damage the contralateral TON and produce symptoms that cross midline. Due to dual innervation from the contralateral side, unilateral TON lesions may not produce hypoesthesia.

\section{Treatment}

Before beginning any treatment, it is important to establish the parameters that are expected to be improved. Subjective measurement of pain by the visual analog scale (VAS) or other measures may be affected by depression and insomnia. Other than the neuralgic pain itself, quality of life (QoL) may be benefited by the treatment of chronic pain. In cases of intractable chronic pain, consideration must be made for risks and benefits of options that may not have been well studied. In addition to the available 
options, cognitive behavioral therapy may be beneficial. Moderately strong evidence exists in favor of cognitive behavioral therapy (CBT) in the treatment of chronic pain. CBT is associated with improved social and physical function, as well as $25 \%$ greater ability to cope with pain, than other behavioral therapies, medications and physical therapy. ${ }^{53}$ Due to low risk of adverse events, physical modalities such as ice may be used independently or combined with other treatment options.

Most data regarding treatment of craniofacial neuralgia surrounds the diagnosis of idiopathic TN. Some etiologies of neuralgia are more resistant to treatment than others. For example, no medical therapy has been found to be effective in $\mathrm{TN}$ due to multiple sclerosis and $50 \%$ of individuals have a recurrence by 2 years after a surgical procedure. ${ }^{52}$ Various treatment strategies may need to be administered simultaneously for additive benefit.

\section{Medications}

\section{Transdermal}

Compounded topical analgesics (galenic preparations) have been advocated by compounding pharmacies. ${ }^{54} 27 \%$ of pain physicians reported prescribing these medications. ${ }^{55}$ Many receptors contribute to pain sensation in the periphery, including glutamate receptors of NMDA, sodium channels, transient receptor potential vanilloid-1 (TRPV1), alpha-2 adrenergic receptors, substance $\mathrm{P}$ and cannabinoid receptors. ${ }^{57}$ Topical ketamine cream, clonidine gel, topical gabapentin, topical baclofen and topical phenytoin ${ }^{56}$ have been described in the literature. ${ }^{57}$ However, not all medications may work topically from a mechanistic standpoint.

Care must be taken in evaluating the mechanism of action in considering a medication for topical use. Some medications, for instance ketamine, needs to go through hepatic first pass and be activated by the cytochrome p450 enzymes in order to become active. ${ }^{54}$ As topical application forgoes first pass, ketamine has not been found to be efficacious in placebo-controlled trials for use in diabetic neuropathy, ${ }^{58}$ and postherpetic neuralgia. ${ }^{59}$ Certain medications act on peripheral receptors, while others such as 
clonidine, appear to exert antinociceptive effects at the spinal and supraspinal levels. ${ }^{54}$ This may be the reason, one Cochrane review did not show strong evidence for topical clonidine use in peripheral diabetic neuropathy.$^{60}$ Compounded medications, in general, may have a higher rate of placebo effect. Due to high placebo rate ${ }^{54}$ for handmade compounded products, uncontrolled trials may not provide the amount of scientific certainty necessary to make clinical decisions. Consequently, when a medication, such as diclofenac gel is found to be effective for neuropathic pain, ${ }^{61}$ controlled trials need to be pursued.

Strong evidence exists for $8 \%$-capsaicin ointment and 5\%-lidocaine patches for postherpetic neuralgia. ${ }^{63}$ Capsaicin, the active component of chili peppers, activates TRPV1 channels, resulting in temporary burning sensation followed by numbness of the skin after substance $\mathrm{P}$ is depleted, and the nociceptors are disabled. Despite the intensity of the initial burning sensation, $98 \%$ of individuals tolerate the capsaicin $8 \%$ patch well. ${ }^{63}$

Due to negligible systemic absorption, lidocaine patch 5\% does not produce arrhythmia or toxicity and is therefore recommended as the first-line therapy for treating postherpetic neuralgia in elderly patients. Similarly, lidocaine ointment may provide short-term pain reduction and have minimal side effects. ${ }^{64} 30 \%$ of pain reduction was seen in patients with neuropathic pain, who had an increase in at least one of the qualitative sensory test thresholds, suggesting certain phenotypes may better benefit from topical medications more than others. ${ }^{61}$ Topical aspirin/diethyl ether mixture was found to be superior to placebo in treating acute and post-herpetic neuralgia. ${ }^{62}$

\section{Enteral}

No strong evidence exists for any one medication for the treatment of craniofacial neuralgias. Between 1962 and 2010, only four high quality studies have been conducted on the use of anticonvulsants for the treatment of craniofacial pain. ${ }^{65}$ As a result, there is limited evidence supporting the efficacy of commonly used anticonvulsants for treatment of such disorders. More high quality data are needed on the efficacy of various medications specifically in the treatment of traumatic facial neuropathies because of 
possible differences in response to treatment. Therapeutic response in painful traumatic trigeminal neuropathy (PTTN) was found by one study to be decreased than in classic trigeminal neuropathy (CTN). Only $11 \%$ of PTTN group experienced more than $50 \%$ reduction in pain intensity compared to $74 \%$ of CTN. ${ }^{66}$ Many guidelines recommend carbamazepine as the first line agent for TN. ${ }^{67,68}$

The dibenzazepines class of medications, which includes carbamazepine (CBZ), oxcarbazepine (OXC) and eslicarbazepine (ELS), appear to be the most useful when it comes to facial neuralgias. Current evidence-based treatment guidelines recommend CBZ (200-1200 mg/day) or OXC (600$1800 \mathrm{mg}$ /day) as first-line therapy for TN. ${ }^{69}$ Typical maintenance dose is $200-600 \mathrm{mg} /$ day for CBZ and doses up to $2400 \mathrm{mg}$ may be necessary. Full dosage may not be reached due to side effects, in which case, another anticonvulsant or medication from another class may be added on. ${ }^{70}$ With CBZ, $60-70 \%$ of patients achieve a minimum $50 \%$ pain reduction. The number needed to treat (NNT) to achieve a substantial pain relief is $1.7-1.8$, while the number needed to harm $(\mathrm{NNH})$ is $3.4 .^{71}$

Anticonvulsants used in facial pain can be associated with significant side effects. A small percentage $(6 \%-10 \%)$ of patients are intolerant to $\mathrm{CBZ}$ used for $\mathrm{TN} .{ }^{72} \mathrm{~A}$ rare but potentially fatal side effect of CBZ is Stevens-Johnson syndrome and toxic epidermal necrolysis, which require immediate intervention. ${ }^{73}$ More commonly, both CBZ and OXC use in craniofacial neuralgia are associated with somnolence $(18 \%)$, memory impairment $(23 \%)$ and unsteadiness $(12 \%) \cdot{ }^{72}$ In another study, memory deficits and fatigue was least common in OXC compared to other anticonvulsants. ${ }^{74}$ Due to its potent antineuralgic properties in the absence of significant side effects OXC may be useful in the management of intractable trigeminal neuralgia. ${ }^{75}$ However, even OXC's antineuralgic effects can be short-lived and may not prevent need for surgical intervention. ${ }^{75}$ Female gender experienced more side effects than males. ${ }^{76}$ As a higher proportion of ELS than OXC is metabolized into the active metabolite Slicarbazepine, ELS may exert an even stronger effect with a cleaner side effect profile than OXC. Several case reports have shown that when CBZ provides good pain control but intolerable side effects switching to ELS was effective and well-tolerated. ${ }^{77-79}$ More studies are needed on ELS. 
When intolerance to $\mathrm{CBZ}$ is recognized, second-line treatment for $\mathrm{TN}$, lamotrigine (400 mg/day) may be added on.$^{80}$ Alternative treatment options include other antiepileptic drugs such as lamotrigine, gabapentin, and pregabalin. ${ }^{81}$ In TN, gabapentin has shown efficacy alone and in combination with local injections of ropivicaine. ${ }^{82}$ When non-anticonvulsant drug tizanidine was trialed in adjunct to CBZ for management of TN high adverse event rates were seen with the combination. ${ }^{83,84}$

Antidepressants with mixed serotonin/noradrenaline (e.g. amitriptyline and nortriptyline) or specific noradrenaline reuptake-inhibitors (e.g duloxetine) are superior to selective serotonin reuptake inhibitors (SSRI) in managing chronic pain. ${ }^{85}$ The NNT for amitriptyline to achieve moderate pain relief in polyneuropathies is 2 while the NNT is 4 for both venlafaxine and duloxetine in treatment of atypical facial pain and diabetic neuropathy respectively, ${ }^{85}$ making amitriptyline a useful medication in the treatment of craniofacial neuralgias.

When TN occurs due to herpes zoster virus, nucleoside analogue class of medications including acyclovir, famciclovir and valacyclovir inhibit the replication of varicella zoster virus thereby reducing the severity and duration of the acute neuritic attack as well as the risk of post-herpetic neuralgia. ${ }^{86}$ For postherpetic and other causes, the anticonvulsive agents, carbamazepine or oxcarbazepine, constitute the first-line treatment. ${ }^{87}$

Cannabis and cannabis-based products are gaining popularity in the general public, and knowledge of these agents in the management of pain may be useful. Over 450 different compounds can be extracted from the cannabis plant but two phytocannabinoids have been most studied in a medical context: 1. Delta 9-tetrahydrocannabinol (THC), and 2. Cannabidiol (CBD). Of the receptors, cannabinoid 1 (CB1) and cannabinoid 2 (CB2) receptors are responsible for analgesia from THC. ${ }^{88} \mathrm{THC}$ agonism at $\mathrm{CB} 1$ is responsible for psychoactive effects of cannabis. ${ }^{88} \mathrm{CBD}$ acts on several receptors (e.g. 5- $\mathrm{HT}_{1 \mathrm{~A}}$, $\mathrm{CB}_{1}$, GPR55, TRPV1, PPAR $\gamma$, anandamide and adenosine) and these are being studied for possible analgesic and anxiolytic effects. ${ }^{88-94}$ No high-quality evidence exists for cannabis-based product including marijuana in any chronic neuropathic pain condition, ${ }^{95}$ however early studies show promise.${ }^{96}$ Adverse 
effects of somnolence, confusion and psychosis may limit the use in certain individuals. The Canadian Pain Society recommended cannabis-based medicines as third-line therapy for chronic neuropathic pain syndromes if established therapies failed..$^{96}$ The Neuropathic Pain Special Interest Group (NeuPSIG) gave a weak recommendation against cannabis-based treatments. ${ }^{97}$

\section{Procedural treatment}

Several interventions have been tried for TN include rhizotomy, radiofrequency ablation, balloon compression, cryoablation, and botulinum toxin injections, but none have been found with high-level evidence for them. Interventions may carry risks, such as local infection, bleeding, damage of underlying structures including the nerve itself. Implantable devices may carry additional long-term risks such as hardware malfunction, ongoing risk of reinfection and possibility of need for revision surgeries.

Ultrasound-guided cryoneurablation of the proximal GON has been described but needs to be further studied. ${ }^{98}$ Several systematic reviews provide evidence for the safety and efficacy of botulinum toxin in the management of TN and post-herpetic neuralgias..$^{99,100}$

Nerve blocks

Current literature does not have sufficient evidence for or against nerve blocks for craniofacial neuralgias. ${ }^{101}$ Once practical and theoretical concerns are considered, the risk in administering nerve blocks may be lower. In patients allergic reaction to local anesthesia, consider corticosteroids only. ${ }^{102}$ Lidocaine may need to be avoided and the number of nerve blocks per session may need to be limited in the elderly in order to overcome blood pressure fluctuations. ${ }^{103}$ Due to concern for teratogenicity, in pregnant patients, lidocaine (FDA category B) should be used over bupivacaine (FDA category C) and bethamethasone and dexamethasone should be avoided as they can affect fetal lung development. ${ }^{101}$ In those with prior vasovagal attacks, the nerve block may be performed in a supine position. ${ }^{101}$ If there is an open skull defect in the area of injection due to prior craniotomy, nerve block may need to be avoided due to risk of intracranial diffusion of anesthetic agent with resultant syncope and coma. ${ }^{104,105}$ 
Anticoagulation and antiplatelet therapy are not contraindications to nerve blocks. Compression of the injection site afterwards may aid in preventing hematoma formation. ${ }^{101}$ As corticosteroids can result in cosmetic concerns such as alopecia and cutaneous atrophy, risks of corticosteroids in prominent areas of the face and scalp use must be explained to patients. ${ }^{106}$ If methylprednisolone must be used, a small dose must be used. ${ }^{106}$

Non-invasive neuromodulation techniques are an attractive treatment option with excellent safety profiles; however, their use has not been supported by high-quality trials yet. The International Neuromodulation Society has approved the use of extracranial nerve stimulation in the treatment of headaches and other disorders of the head with an aim to perfect targets outside the cranium. ${ }^{107}$ There is moderate evidence for occipital nerve stimulation in treating occipital neuralgia. ${ }^{108}$ Transcutaneous neurostimulation of supraorbital nerve for prevention of primary headaches was tried with an external device and was found to be safe and effective in a placebo-controlled trial; ${ }^{109}$ however, one study reported poor tolerance. ${ }^{110}$ Transcutaneous vagal nerve stimulation has also been shown to help with migraines. ${ }^{111}$

Further, wireless peripheral nerve stimulators have been developed and are beginning to be trialed. The miniature wireless neurostimulator is placed percutaneously adjacent to the nerves needing stimulation. The implantation is minimally invasive and reversible. The device has not only showed feasibility in a preliminary study for the treatment of craniofacial neuralgias, ${ }^{112}$ but also extraordinary pain control has been demonstrated in cases of supraorbital neuralgia ${ }^{113}$ and PIFP. ${ }^{114}$

In comparing glycerol rhizotomy, radiofrequency thermocoagulation and balloon compression for idiopathic TN, radiofrequency thermocoagulation was associated with higher odds for immediate pain relief and anesthesia, while those in the balloon compression group had a higher risk of post-operative mastication weakness and diplopia. ${ }^{115}$ Different radiofrequency approaches were compared systematically and combined continuous radiofrequency achieved a greater effect and safety in treatment of TN than 
continuous or pulsed approaches. ${ }^{116}$ Medium temperature range was found to be better for continuous approach and higher temperature range in pulsed approach, especially in the elderly. ${ }^{116}$

Surgical treatment

Microvascular decompression (MVD) or ablative procedures may be pursued when pharmacotherapy is ineffective or intolerable in idiopathic TN. ${ }^{117}$ Compared to gamma knife radiosurgery (GKRS), MVD has been shown to be more efficacious and posed fewer complications of facial numbness and dysesthetic pain in idiopathic TN. ${ }^{117}$ When GKRS fails, MVD may provide better likelihood of complete pain relief as opposed to repeat GKRS. ${ }^{118}$ MVD may pose small risk (less than 3\% each) of incisional infection, facial palsy, CSF leak and hearing deficits and risk of mortality was $0.1 \% .{ }^{119}$

\section{Future Studies}

The female gender has a higher prevalence for craniofacial pain with exceptions of trigeminal autonomic cephalgias and glossopharyngeal neuralgias. ${ }^{120}$ Future research needs to focus on sex-based factors that contribute to pain and gender-based treatment strategies. According to one large systematic review, most literature surrounding $\mathrm{TN}$ collected data on pain and side effects but very few collected data on the impact on functionality and emotional consequences of the disease and its treatment. ${ }^{121}$ In order to improve health outcomes and reduce cost of healthcare, outcomes that are important for patients need to be better identified. While anticonvulsants are effective in treating idiopathic $\mathrm{TN}$, few studies have high levels of evidence and high-quality randomized controlled trials are lacking in this area of medicine. ${ }^{122}$ Traumatic craniofacial neuropathies are also not well studies. These may be areas for further study. Due to intolerable side effects to enteral medications, topical medications, physical modalities and simpler interventions such as transnasal sphenopalatine ganglion block, ${ }^{123}$ may be preferred by patients. However, good quality data is limited in these areas and may be opportunities for further study.

\section{Conclusion}


Periorbital pain is mediated by infratrochlear, supratrochlear, supraorbital, lacrimal and infraorbital nerves. Periauricular neuralgia may involve the auriculotemporal nerve, the great auricular nerve, and the nervus intermedius. Posterior head neuralgias can be transmitted by the greater occipital nerve, lesser occipital nerve and third occipital. Knowledge of their distribution and landmarks for palpation can help with nerve blockade. Numerous treatment options exist, most have not been very well studied for traumatic craniofacial neuropathies. Among the studied medications, carbamazepine and microvascular decompression carries most benefit for treatment of idiopathic $\mathrm{TN}$. 


\section{References}

1. Cramer, G.D. The Cervical Spine In Cramer GD, Darby SA (Eds). (2014). Clinical Anatomy of the Spine, Spinal Cord, and ANS (Third Edition). Lombard, IL: Mosby.

2. Okeson, J.P. DMD. 2014. Bell's Orofacial Pains - 7th Ed. Hanover Park, IL. Quintessence Publishing Co, Inc.

3. Hammond, F. M., Katta-Charles, S.D., Cranial Nerves In Zasler, N. D., Katz, D. I., \& Zafonte, R. D. (Eds.). (2021). Brain injury medicine: Principles and practice. NY, NY: Demos Medical Publishing. Manuscript submitted for publication

4. Gambeta, E., Chichorro, JG, Zamponi, GW. (2020). Trigeminal neuralgia: An overview from pathophysiology to pharmacological treatments. Mol Pain. 2020;16:1744806920901890. doi:10.1177/1744806920901890

5. Zakrzewska J.M., Wu J., Mon-Williams, M., Phillips N., Pavitt, S.H. (2017). Evaluating the impact of trigeminal neuralgia. Pain. 2017;158(6):1166-1174.

doi:10.1097/j.pain.0000000000000853

6. Devor, M. , Amir, R. \& Rappaport, Z. H. (2002). Pathophysiology of Trigeminal Neuralgia: The Ignition Hypothesis. The Clinical Journal of Pain, 18(1), 4-13.

7. De Toledo, I. P., Conti Réus, J., Fernandes, M., Porporatti, A. L., Peres, M. A., Takaschima, A., Linhares, M. N., Guerra, E., \& De Luca Canto, G. (2016). Prevalence of trigeminal neuralgia: A systematic review. Journal of the American Dental Association (1939), 147(7), 570-576.e2. https://doi.org/10.1016/j.adaj.2016.02.014

8. Smith, M.H., Lung, K.E. (2006). Nerve injuries after dental injection: A review of the literature. $J$ Can Dent Assoc 2006; 72: 559-564.

9. Sambrook, P.J., Goss, A.N. (2011). Severe adverse reactions to dental local anaesthetics: Prolonged mandibular and lingual nerve anaesthesia. Aust Dent J 2011; 56: 154-159. 
10. Campbell, R.L., Parks, K.W., Dodds, R.N. (1990). Chronic facial pain associated with endodontic therapy. Oral Surg Oral Med Oral Pathol 1990; 69: 287-290.

11. Heir, G.M,. Nasri-Heir, C., Thomas, D. (2012). Complex regional pain syndrome following trigeminal nerve injury: Report of 2 cases. Oral Surg Oral Med Oral Path Oral Rad 2012; 114: 733-739.

12. Pareja, J. A., López-Ruiz, P., Mayo, D., Villar-Quiles, R. N., Cárcamo, A., Gutiérrez-Viedma, Á., Lastarria, C. P., Romeral, M., Yangüela, J., \& Cuadrado, M. L. (2017). Supratrochlear Neuralgia: A Prospective Case Series of 15 Patients. Headache, 57(9), 1433-1442. https://doi.org/10.1111/head.13158

13. Cho, H. J., Bloomberg, J., \& Nichols, J. (2017). Giant cell arteritis. Disease-a-month : DM, 63(3), 88-91. https://doi.org/10.1016/j.disamonth.2016.10.006

14. Agrawal, S. M., \& Kambalimath, D. H. (2010). Trigeminal neuralgia involving supraorbital and infraorbital nerves. National journal of maxillofacial surgery, 1(2), 179-182. https://doi.org/10.4103/0975-5950.79226

15. Sjaastad, O., Petersen, H. C., \& Bakketeig, L. S. (2005). Supraorbital neuralgia. Vågå study of headache epidemiology. Cephalalgia : an international journal of headache, 25(4), 296-304. https://doi.org/10.1111/j.1468-2982.2004.00856.x

16. Chavarría-Miranda, A., Guerrero, A. L., \& García-Azorín, D. (2018). Sequential Presentation of Ipsilateral Supraorbital and Lacrimal Neuralgias in a Patient. Pain medicine (Malden, Mass.), 19(12), 2577-2579. https://doi.org/10.1093/pm/pny103

17. Younger D.S. (2019). Giant Cell Arteritis. Neurologic clinics, 37(2), 335-344. https://doi.org/10.1016/j.ncl.2019.01/008

18. Cuadrado, M. L., Gutiérrez-Viedma, Á., Silva-Hernández, L., Orviz, A., \& García-Moreno, H. (2017). Lacrimal Nerve Blocks for Three New Cases of Lacrimal Neuralgia. Headache, 57(3), 460-466. https://doi.org/10.1111/head.12985 
19. Gray's anatomy : the anatomical basis of clinical practice. Standring, Susan (41 ed.).

[Philadelphia]. 2016. ISBN 978-0-7020-5230-9. OCLC 920806541.

20. Beigi, B., Beigi, M., Niyadurupola, N., Saldana, M., El-Hindy, N., \& Gupta, D. (2017).

Infraorbital Nerve Decompression for Infraorbital Neuralgia/Causalgia following Blowout Orbital Fractures: A Case Series. Craniomaxillofacial trauma \& reconstruction, 10(1), 22-28. https://doi.org/10.1055/s-0036-1592095

21. Sykes, J.M. (2009). Complications of Facial Implants in Complications In D.W. Eisele and R.V. Smith (Eds.) Head and Neck Surgery 2nd ed. Philadelphia: Mosby Elsevier; 2009. pp. 671-6.

22. Ross, A.K., Bryskin, R.B. (2011). Regional Anesthesia In P.J. Davis, F.P. Cladis, E.K. Motoyoma (Eds.) Smith's Anesthesia for Infants and Children. $8^{\text {th }}$ ed. Philadelphia: Elsevier Mosby; pp. 452-458.

23. Headache Classification Subcommittee of the International Headache Society (IHS). (2013). The International Classification of Headache Disorders, 3rd edition (beta version). Cephalalgia : an international journal of headache, 33(9), 629-808. https://doi.org/10.1177/0333102413485658

24. Benoliel, R., \& Gaul, C. (2017). Persistent idiopathic facial pain. Cephalalgia, 37(7), 680-691. https://doi.org/10.1177/0333102417706349

25. Barral, J., Croibier, A. (2009). Evaluation and treatment of cranial nerves. In J. Barral and A. Croibier. (Eds.) Manual Therapy for the Cranial Nerves, Churchill Livingstone; pp 37-49. https://doi.org/10.1016/B978-0-7020-3100-7.50011-2.

26. Komarnitki, I., Andrzejczak-Sobocinska, A., Tomcyzk, J., Deszczynska, K., \& Ciszek, B. (2012). Clinical anatomy of the auriculotemporal nerve in the area of the infratemporal fossa. Folia morphologica, 71(3), 187-193.

27. Speciali, J. G., \& Gonçalves, D. A. (2005). Auriculotemporal neuralgia. Current pain and headache reports, 9(4), 277-280. https://doi.org/10.1007/s11916-005-0037-0

28. Gonzalez-Garcia, R., Rodriguez-Campo, F.J., Escorial-Hernandez, V., Munoz-Guerra, M.F.,Sastre-Perez, J. L. (2006). Complications of temporomandibular joint arthroscopy: a 
retrospective analytic study of 670 arthroscopic procedures. Journal of oral and maxillofacial surgery: official journal of the American Association of Oral and Maxillofacial Surgeons, 64(11),,1587-1591. https://doi.org/10.1016/j.jos.2005.12.058

29. Linke, R., Wollenberg, B., \& Schröder, U. (2012). Diagnostik und Management von Schmerzsyndromen nach Parotidektomie [Diagnosis and management of pain syndromes following parotidectomy]. $H N O, 60(8), 725-729$. https://doi.org/10.1007/s00106-011-2415-8

30. Nusair, Y. M., \& Dickenson, A. J. (2003). Great auricular causalgia: an unusual complication of excision of the submandibular gland. The British journal of oral \& maxillofacial surgery, 41(5), 334-335. https://doi.org/10.1016/s0266-4356(03)00116-5

31. Duvall, J. R., Garza, I., Kissoon, N. R., \& Robertson, C. E. (2020). Great Auricular Neuralgia: Case Series. Headache, 60(1), 247-258. https://doi.org/10.1111/head.13690

32. Park, S. W., Choi, J. Y., \& Jung, K. J. (2018). Management of Great Auricular Neuralgia Confirmed by Electrophysiologic Examination: A Case Report. Journal of oral \& facial pain and headache, 32(32), e53-e56. https://doi.org/10.11607/ofph.2144

33. Eghtesadi, M., Leroux, E., \& Vargas-Schaffer, G. (2017). A case report of complex auricular neuralgia treated with the great auricular nerve and facet blocks. Journal of pain research, 10, 435-438. https://doi.org/10.2147/JPR.S126923

34. Rhoton, A. L., Jr, Kobayashi, S., \& Hollinshead, W. H. (1968). Nervus intermedius. Journal of neurosurgery, 29(6), 609-618. https://doi.org/10.3171/jns.1968.29.6.0609

35. Sellers, A., \& Simmons, M. (2019). Glossopharyngeal Neuralgia: A Multidimensional Challenge. South Dakota medicine : the journal of the South Dakota State Medical Association, 72(9), 393-395.

36. Tang, I.P., Freeman, S.R., Kontorinis, G., Tang, M. Y., Rutherford, S.A., King, A.T.,\&Lloyd, S.K. (2014). Geniculate neuralgia: a systematic review. The journal of laryngology and otology, 128(5), 394-399. 
37. George, D.D., Ridder, T.S. (2020). Geniculate neuralgia in an adolescent treated via sectioning of the nervus intermedius and microvascular decompression. Journal of neurosurgery. Pediatrics, 1 4. Advance online publication.

38. Kuhweide, R., Van de Steene, V., Vlaminck, S., et al. Ramsay Hunt syndrome: pathophysiology of cochleovestibular symptoms. J Laryngol Otol, 116 (10) (2002), p. 844-848

39. Das, M.J., Al Khalili, Y., Jugular Foramen Syndrome (Vernet) [Updated 2020 Mar 4]. In: StatPearls [Internet]. Treasure Island (FL): StatPearls Publishing; 2020 Ja-. Available from: https://www.ncbi.nlm.nih.gov/books/NBK549871

40. Blumenfeld, A., \& Nikolskaya, G. (2013). Glossopharyngeal neuralgia. Current pain and headache reports, 17(7), 343.

41. Sweet, J. A., Mitchell, L. S., Narouze, S., Sharan, A. D., Falowski, S. M., Schwalb, J. M., Machado, A., Rosenow, J. M., Petersen, E. A., Hayek, S. M., Arle, J. E., \& Pilitsis, J. G. (2015). Occipital Nerve Stimulation for the Treatment of Patients With Medically Refractory Occipital Neuralgia: Congress of Neurological Surgeons Systematic Review and Evidence-Based Guideline. Neurosurgery, 77(3), 332-341. https://doi.org/10.1227/NEU.0000000000000872

42. Bogduk, N. Clinical Anatomy of the Cervical Dorsal Rami. Spine (Phila. Pa. 1976) 7, 319-330 (1982).

43. Belvís, R., \& Guerrero, Á. L. (2019). Benito's neuralgia: the first description of the occipital neuralgia was made for Spanish doctors at the beginning of the nineteenth century. Neurological sciences : official journal of the Italian Neurological Society and of the Italian Society of Clinical Neurophysiology, 40(11), 2425-2429. https://doi.org/10.1007/s10072-019-03734-5

44. Choi, I. \& Jeon, S. R. Neuralgias of the head: Occipital neuralgia. J Korean Med Sci 31, 479-488 (2016).

45. Standring, S., Borley, N. R., Collins, P., Crossman, A. R., Gatzoulis, M. A., Healy, J. C., Johnson, D., Mahadevan, V., Newell, R. L. M., \& Wigley, C. B. Gray's anatomy. The anatomical basis of clinical practice. Edinburgh, Elsevier, 2008. 
46. Kim, E., \& Cucchiaro, G. (2019). Occipital Nerve Blocks for Relief of Headaches in Patients With Ventriculoperitoneal Shunts: A Case Series. Journal of child neurology, 34(11), 674-678. https://doi.org/10.1177/0883073819853079

47. Hoppenfeld J.D. 2010. Cervical facet arthropathy and occipital neuralgia: Headache culprits. Curr Pain Headache Rep 14:418- 423.

48. Cesmebasi, A., Muhleman, M. A., Hulsberg, P., Gielecki, J., Matusz, P., Tubbs, R. S., \& Loukas, M. (2015). Occipital neuralgia: anatomic considerations. Clinical anatomy (New York, N.Y.), 28(1), 101-108. https://doi.org/10.1002/ca.22468

49. Tubbs, R. S., Salter, E. G., Wellons, J. C., Blount, J. P., \& Oakes, W. J. (2007). Landmarks for the identification of the cutaneous nerves of the occiput and nuchal regions. Clinical anatomy (New York, N.Y.), 20(3), 235-238. https://doi.org/10.1002/ca.20297

50. Khavanin, N., Carl, H. M., Yang, R., \& Dorafshar, A. H. (2019). Surgical "Safe Zone": Rapid Anatomical Identification of the Lesser Occipital Nerve. Journal of reconstructive microsurgery, 35(5), 341-345. https://doi.org/10.1055/s-0038-1676601

51. Cesmebasi, A., Muhleman, M. A., Hulsberg, P., Gielecki, J., Matusz, P., Tubbs, R. S., \& Loukas, M. (2015). Occipital neuralgia: anatomic considerations. Clinical anatomy (New York, N.Y.), 28(1), 101-108. https://doi.org/10.1002/ca.22468

52. Zakrzewska, J. M., Wu, J., \& Brathwaite, T. S. (2018). A Systematic Review of the Management of Trigeminal Neuralgia in Patients with Multiple Sclerosis. World neurosurgery, 111, 291-306. https://doi.org/10.1016/j.wneu.2017.12.147

53. Swedish Council on Health Technology Assessment. (2006). Methods of Treating Chronic Pain: A Systematic Review. Swedish Council on Health Technology Assessment (SBU).

54. Anitescu, M., Benzon, H. T., \& Argoff, C. E. (2013). Advances in topical analgesics. Current opinion in anaesthesiology, 26(5), 555-561. https://doi.org/10.1097/01.aco.0000432514.00446.22 
55. Ness, T. J., Jones, L., \& Smith, H. (2002). Use of compounded topical analgesics--results of an Internet survey. Regional anesthesia and pain medicine, 27(3), 309-312. https://doi.org/10.1053/rapm.2002.31212

56. Kopsky, D. J., \& Keppel Hesselink, J. M. (2017). Topical phenytoin for the treatment of neuropathic pain. Journal of pain research, 10, 469-473. https://doi.org/10.2147/JPR.S129749

57. Knezevic, N. N., Tverdohleb, T., Nikibin, F., Knezevic, I., \& Candido, K. D. (2017). Management of chronic neuropathic pain with single and compounded topical analgesics. Pain management, 7(6), 537-558. https://doi.org/10.2217/pmt-2017-0020

58. Mahoney, J. M., Vardaxis, V., Moore, J. L., Hall, A. M., Haffner, K. E., \& Peterson, M. C. (2012). Topical ketamine cream in the treatment of painful diabetic neuropathy: a randomized, placebo-controlled, double-blind initial study. Journal of the American Podiatric Medical Association, 102(3), 178-183. https://doi.org/10.7547/1020178

59. Barros, G. A., Miot, H. A., Braz, A. M., Ramos, F., \& Borges, M. A. (2012). Topical (S)ketamine for pain management of postherpetic neuralgia. Anais brasileiros de dermatologia, 87(3), 504-505. https://doi.org/10.1590/s0365-05962012000300032

60. Wrzosek, A., Woron, J., Dobrogowski, J., Jakowicka-Wordliczek, J., \& Wordliczek, J. (2015). Topical clonidine for neuropathic pain. The Cochrane database of systematic reviews, 8(9), CD010967. https://doi.org/10.1002/14651858.CD010967.pub2

61. Ahmed, S. U., Zhang, Y., Chen, L., Cohen, A., St Hillary, K., Vo, T., Houghton, M., \& Mao, J. (2015). Effect of 1.5\% Topical Diclofenac on Clinical Neuropathic Pain. Anesthesiology, 123(1), 191-198. https://doi.org/10.1097/ALN.0000000000000693

62. De Benedittis, G., Besana, F., \& Lorenzetti, A. (1992). A new topical treatment for acute herpetic neuralgia and post-herpetic neuralgia: the aspirin/diethyl ether mixture. An open-label study plus a double-blind controlled clinical trial. Pain, 48(3), 383-390. https://doi.org/10.1016/0304$\underline{3959(92) 90088-\mathrm{S}}$ 
63. Peppin, J. F., Majors, K., Webster, L. R., Simpson, D. M., Tobias, J. K., \& Vanhove, G. F. (2011). Tolerability of NGX-4010, a capsaicin $8 \%$ patch for peripheral neuropathic pain. Journal of pain research, 4, 385-392. https://doi.org/10.2147/JPR.S22954

64. Jensen, T. S., Madsen, C. S., \& Finnerup, N. B. (2009). Pharmacology and treatment of neuropathic pains. Current opinion in neurology, 22(5), 467-474. https://doi.org/10.1097/WCO.0b013e3283311e13

65. Martin, W. J., \& Forouzanfar, T. (2011). The efficacy of anticonvulsants on orofacial pain: a systematic review. Oral surgery, oral medicine, oral pathology, oral radiology, and endodontics, 111(5), 627-633. https://doi.org/10.1016/j.tripleo.2011.01.033

66. Haviv, Y., Zadik, Y., Sharav, Y., \& Benoliel, R. (2014). Painful traumatic trigeminal neuropathy: an open study on the pharmacotherapeutic response to stepped treatment. Journal of oral \& facial pain and headache, 28(1), 52-60. https://doi.org/10.11607/jop.1154

67. National Institute for Health and Care Excellence (NICE). Neuropathic pain: the pharmacological management of neuropathic pain in adults in non-specialist settings. 2013.

68. Bendtsen, L., Birk, S., Kasch, H., Aegidius, K., Sørensen, P. S., Thomsen, L. L., Poulsen, L., Rasmussen, M. J., Kruuse, C., Jensen, R., \& Danish Headache Society (2012). Reference programme: diagnosis and treatment of headache disorders and facial pain. Danish Headache Society, 2nd Edition, 2012. The journal of headache and pain, 13 Suppl 1(Suppl 1), S1-S29. https://doi.org/10.1007/s10194-011-0402-9

69. Obermann M. (2010). Treatment options in trigeminal neuralgia. Therapeutic advances in neurological disorders, 3(2), 107-115. https://doi.org/10.1177/1756285609359317

70. Di Stefano, G., Truini, A., \& Cruccu, G. (2018). Current and Innovative Pharmacological Options to Treat Typical and Atypical Trigeminal Neuralgia. Drugs, 78(14), 1433-1442. https://doi.org/10.1007/s40265-018-0964-9 
71. Cruccu, G., Gronseth, G., Alksne, J., Argoff, C., Brainin, M., Burchiel, K., Nurmikko, T., Zakrzewska, J. M., American Academy of Neurology Society, \& European Federation of Neurological Society (2008). AAN-EFNS guidelines on trigeminal neuralgia management. European journal of neurology, 15(10), 1013-1028. https://doi.org/10.1111/j.14681331.2008.02185.x

72. Taylor, J. C., Brauer, S., \& Espir, M. L. (1981). Long-term treatment of trigeminal neuralgia with carbamazepine. Postgraduate medical journal, 57(663), 16-18. https://doi.org/10.1136/pgmj.57.663.16

73. Garcia, J. B., Ferro, L. S., Carvalho, A. B., da Rocha, R. M., \& de Souza, L. M. (2010). Severe carbamazepine-induced cutaneous reaction in the treatment of post-herpetic neuralgia. Case report. Revista brasileira de anestesiologia, 60(4), 429-437. https://doi.org/10.1016/S0034$\underline{7094(10) 70053-2}$

74. Tentolouris-Piperas, V., Lee, G., Reading, J., O'Keeffe, A. G., Zakrzewska, J. M., \& Cregg, R. (2018). Adverse effects of anti-epileptics in trigeminal neuralgiform pain. Acta neurologica Scandinavica, 137(6), 566-574. https://doi.org/10.1111/ane.12901

75. Zakrzewska, J. M., \& Patsalos, P. N. (1989). Oxcarbazepine: a new drug in the management of intractable trigeminal neuralgia. Journal of neurology, neurosurgery, and psychiatry, 52(4), 472476. https://doi.org/10.1136/jnnp.52.4.472

76. Besi, E., Boniface, D. R., Cregg, R., \& Zakrzewska, J. M. (2015). Comparison of tolerability and adverse symptoms in oxcarbazepine and carbamazepine in the treatment of trigeminal neuralgia and neuralgiform headaches using the Liverpool Adverse Events Profile (AEP). The journal of headache and pain, 16, 563. https://doi.org/10.1186/s10194-015-0563-z

77. Alcántara Montero, A., \& Sánchez Carnerero, C. I. (2019). Eslicarbazepine acetate for neuropathic pain, headache, and cranial neuralgia: Evidence and experience. Acetato de eslicarbazepina en dolor neuropático, cefaleas y neuralgias craneales: Evidencia y 
experiencia. Neurologia (Barcelona, Spain), 34(6), 386-395.

https://doi.org/10.1016/j.nrl.2016.11.009

78. Sanchez-Larsen, A., Sopelana, D., Diaz-Maroto, I., Perona-Moratalla, A. B., Gracia-Gil, J., García-Muñozguren, S., Palazón-García, E., \& Segura, T. (2018). Assessment of efficacy and safety of eslicarbazepine acetate for the treatment of trigeminal neuralgia. European journal of pain (London, England), 22(6), 1080-1087. https://doi.org/10.1002/ejp.1192

79. Cuadrado, M. L., Aledo-Serrano, Á., \& Ruiz-Álvarez, L. (2015). Eslicarbazepine acetate for a patient with highly resistant epicrania fugax. Pain practice: the official journal of World Institute of Pain, 15(1), E27. https://doi.org/10.1111/papr.12261

80. Zakrzewska, J. M., Chaudhry, Z., Nurmikko, T. J., Patton, D. W., \& Mullens, E. L. (1997). Lamotrigine (lamictal) in refractory trigeminal neuralgia: results from a double-blind placebo controlled crossover trial. Pain, 73(2), 223-230. https://doi.org/10.1016/s0304-3959(97)00104-8

81. Zakrzewska, J. M., \& Linskey, M. E. (2014). Trigeminal neuralgia. BMJ (Clinical research ed.), 348, g474. https://doi.org/10.1136/bmj.g474

82. Lemos, L., Flores, S., Oliveira, P., \& Almeida, A. (2008). Gabapentin supplemented with ropivacain block of trigger points improves pain control and quality of life in trigeminal neuralgia patients when compared with gabapentin alone. The Clinical journal of pain, 24(1), 64-75. https://doi.org/10.1097/AJP.0b013e318158011aZhang, J., Yang, M., Zhou, M., He, L., Chen, N., \& Zakrzewska, J. M. (2013). Non-antiepileptic drugs for trigeminal neuralgia. The Cochrane database of systematic reviews, (12), CD004029. https://doi.org/10.1002/14651858.CD004029.pub4

83. Yang, M., Zhou, M., He, L., Chen, N., \& Zakrzewska, J. M. (2011). Non-antiepileptic drugs for trigeminal neuralgia. The Cochrane database of systematic reviews, (1), CD004029. https://doi.org/10.1002/14651858.CD004029.pub3

84. Saarto, T., \& Wiffen, P. J. (2007). Antidepressants for neuropathic pain. The Cochrane database of systematic reviews, (4), CD005454. https://doi.org/10.1002/14651858.CD005454.pub2 
85. Kanbayashi, Y., \& Hosokawa, T. (2013). Vaccination against and treatment of acute herpes zoster for prevention of post-herpetic neuralgia. Current pain and headache reports, 17(10), 371. https://doi.org/10.1007/s11916-013-0371-6

86. Feller, L., Khammissa, R., Fourie, J., Bouckaert, M., \& Lemmer, J. (2017). Postherpetic Neuralgia and Trigeminal Neuralgia. Pain research and treatment, 2017, 1681765. https://doi.org/10.1155/2017/1681765

87. Costa, B., Giagnoni, G., Franke, C., Trovato, A. E., \& Colleoni, M. (2004). Vanilloid TRPV1 receptor mediates the antihyperalgesic effect of the nonpsychoactive cannabinoid, cannabidiol, in a rat model of acute inflammation. British journal of pharmacology, 143(2), 247-250. https://doi.org/10.1038/sj.bjp.0705920

88. Iannotti, F. A., Hill, C. L., Leo, A., Alhusaini, A., Soubrane, C., Mazzarella, E., Russo, E., Whalley, B. J., Di Marzo, V., \& Stephens, G. J. (2014). Nonpsychotropic plant cannabinoids, cannabidivarin (CBDV) and cannabidiol (CBD), activate and desensitize transient receptor potential vanilloid 1 (TRPV1) channels in vitro: potential for the treatment of neuronal hyperexcitability. ACS chemical neuroscience, 5(11), 1131-1141. https://doi.org/10.1021/cn5000524

89. Laprairie, R. B., Bagher, A. M., Kelly, M. E., \& Denovan-Wright, E. M. (2015). Cannabidiol is a negative allosteric modulator of the cannabinoid CB1 receptor. British journal of pharmacology, 172(20), 4790-4805. https://doi.org/10.1111/bph.13250

90. Pertwee R. G. (2008). The diverse CB1 and CB2 receptor pharmacology of three plant cannabinoids: delta9-tetrahydrocannabinol, cannabidiol and delta9tetrahydrocannabivarin. British journal of pharmacology, 153(2), 199-215. https://doi.org/10.1038/sj.bjp.0707442

91. Russo, E. B., Burnett, A., Hall, B., \& Parker, K. K. (2005). Agonistic properties of cannabidiol at 5-HT1a receptors. Neurochemical research, 30(8), 1037-1043. https://doi.org/10.1007/s11064$\underline{005-6978-1}$ 
92. Ryberg, E., Larsson, N., Sjögren, S., Hjorth, S., Hermansson, N. O., Leonova, J., Elebring, T., Nilsson, K., Drmota, T., \& Greasley, P. J. (2007). The orphan receptor GPR55 is a novel cannabinoid receptor. British journal of pharmacology, 152(7), 1092-1101. https://doi.org/10.1038/sj.bjp.0707460

93. Straiker, A., Mitjavila, J., Yin, D., Gibson, A., \& Mackie, K. (2015). Aiming for allosterism: Evaluation of allosteric modulators of CB1 in a neuronal model. Pharmacological research, 99, 370-376. https://doi.org/10.1016/j.phrs.2015.07.017

94. Mücke, M., Phillips, T., Radbruch, L., Petzke, F., \& Häuser, W. (2018). Cannabis-based medicines for chronic neuropathic pain in adults. The Cochrane database of systematic reviews, 3(3), CD012182. https://doi.org/10.1002/14651858.CD012182.pub2

95. Hossain, M. Z., Ando, H., Unno, S., \& Kitagawa, J. (2020). Targeting Peripherally Restricted Cannabinoid Receptor 1, Cannabinoid Receptor 2, and Endocannabinoid-Degrading Enzymes for the Treatment of Neuropathic Pain Including Neuropathic Orofacial Pain. International journal of molecular sciences, 21(4), 1423. https://doi.org/10.3390/ijms21041423

96. Moulin, D., Boulanger, A., Clark, A. J., Clarke, H., Dao, T., Finley, G. A., Furlan, A., Gilron, I., Gordon, A., Morley-Forster, P. K., Sessle, B. J., Squire, P., Stinson, J., Taenzer, P., Velly, A., Ware, M. A., Weinberg, E. L., Williamson, O. D., \& Canadian Pain Society (2014). Pharmacological management of chronic neuropathic pain: revised consensus statement from the Canadian Pain Society. Pain research \& management, 19(6), 328-335. https://doi.org/10.1155/2014/754693

97. Finnerup, N. B., Attal, N., Haroutounian, S., McNicol, E., Baron, R., Dworkin, R. H., Gilron, I., Haanpää, M., Hansson, P., Jensen, T. S., Kamerman, P. R., Lund, K., Moore, A., Raja, S. N., Rice, A. S., Rowbotham, M., Sena, E., Siddall, P., Smith, B. H., \& Wallace, M. (2015). Pharmacotherapy for neuropathic pain in adults: a systematic review and meta-analysis. The Lancet. Neurology, 14(2), 162-173. https://doi.org/10.1016/S1474-4422(14)70251-0 
98. Stogicza, A., Trescot, A., \& Rabago, D. (2019). New Technique for Cryoneuroablation of the Proximal Greater Occipital Nerve. Pain practice : the official journal of World Institute of Pain, 19(6), 594-601. https://doi.org/10.1111/papr.12779

99. Shackleton, T., Ram, S., Black, M., Ryder, J., Clark, G. T., \& Enciso, R. (2016). The efficacy of botulinum toxin for the treatment of trigeminal and postherpetic neuralgia: a systematic review with meta-analyses. Oral surgery, oral medicine, oral pathology and oral radiology, 122(1), 6171. https://doi.org/10.1016/j.oooo.2016.03.003

100. Morra, M. E., Elgebaly, A., Elmaraezy, A., Khalil, A. M., Altibi, A. M., Vu, T. L., Mostafa, M. R., Huy, N. T., \& Hirayama, K. (2016). Therapeutic efficacy and safety of Botulinum Toxin A Therapy in Trigeminal Neuralgia: a systematic review and meta-analysis of randomized controlled trials. The journal of headache and pain, 17(1), 63. https://doi.org/10.1186/s10194$\underline{016-0651-8}$

101. Blumenfeld, A., Ashkenazi, A., Napchan, U., Bender, S. D., Klein, B. C., Berliner, R., Ailani, J., Schim, J., Friedman, D. I., Charleston, L., 4th, Young, W. B., Robertson, C. E., Dodick, D. W., Silberstein, S. D., \& Robbins, M. S. (2013). Expert consensus recommendations for the performance of peripheral nerve blocks for headaches--a narrative review. Headache, 53(3), $437-$ 446. https://doi.org/10.1111/head.12053

102. Tobin, J., \& Flitman, S. (2011). Treatment of migraine with occipital nerve blocks using only corticosteroids. Headache, 51(1), 155-159. https://doi.org/10.1111/j.1526-4610.2010.01801.x

103. Sahai-Srivastava, S., \& Subhani, D. (2010). Adverse effect profile of lidocaine injections for occipital nerve block in occipital neuralgia. The journal of headache and pain, 11(6), 519-523. https://doi.org/10.1007/s10194-010-0244-x

104. Okuda, Y., Matsumoto, T., Shinohara, M., Kitajima, T., \& Kim, P. (2001). Sudden unconsciousness during a lesser occipital nerve block in a patient with the occipital bone defect. European journal of anaesthesiology, 18(12), 829-832. https://doi.org/10.1046/j.1365$\underline{2346.2001 .01018 . x}$ 
105. Sprenger, T., \& Seifert, C. L. (2013). Coma after greater occipital nerve blockade in a patient with previous posterior fossa surgery. Headache, 53(3), 548-550. https://doi.org/10.1111/head.12015

106. Lavin, P. J., \& Workman, R. (2001). Cushing syndrome induced by serial occipital nerve blocks containing corticosteroids. Headache, 41(9), 902-904.

107. Deer, T. R., Mekhail, N., Petersen, E., Krames, E., Staats, P., Pope, J., Saweris, Y., Lad, S. P., Diwan, S., Falowski, S., Feler, C., Slavin, K., Narouze, S., Merabet, L., Buvanendran, A., Fregni, F., Wellington, J., Levy, R. M., \& Neuromodulation Appropriateness Consensus Committee (2014). The appropriate use of neurostimulation: stimulation of the intracranial and extracranial space and head for chronic pain. Neuromodulation Appropriateness Consensus Committee. Neuromodulation : journal of the International Neuromodulation Society, 17(6), 551-570. https://doi.org/10.1111/ner.12215

108. Antony, A. B., Mazzola, A. J., Dhaliwal, G. S., \& Hunter, C. W. (2019). Neurostimulation for the Treatment of Chronic Head and Facial Pain: A Literature Review. Pain physician, 22(5), $447-477$.

109. Chou, D. E., Shnayderman Yugrakh, M., Winegarner, D., Rowe, V., Kuruvilla, D., \& Schoenen, J. (2019). Acute migraine therapy with external trigeminal neurostimulation (ACME): A randomized controlled trial. Cephalalgia : an international journal of headache, 39(1), 3-14. https://doi.org/10.1177/0333102418811573

110. Przeklasa-Muszyńska, A., Skrzypiec, K., Kocot-Kępska, M., Dobrogowski, J., Wiatr, M., \& Mika, J. (2017). Non-invasive transcutaneous Supraorbital Neurostimulation (tSNS) using Cefaly ${ }^{\circledR}$ device in prevention of primary headaches. Neurologia i neurochirurgia polska, 51(2), 127-134. https://doi.org/10.1016/j.pjnns.2017.01.004

111. Martelletti, P., Barbanti, P., Grazzi, L., Pierangeli, G., Rainero, I., Geppetti, P., Ambrosini, A., Sarchielli, P., Tassorelli, C., Liebler, E., de Tommaso, M., \& PRESTO Study Group (2018). Consistent effects of non-invasive vagus nerve stimulation (nVNS) for the acute treatment of 
migraine: additional findings from the randomized, sham-controlled, double-blind PRESTO trial. The journal of headache and pain, 19(1), 101. https://doi.org/10.1186/s10194-018-0929-0

112. Weiner, R. L., Garcia, C. M., \& Vanquathem, N. (2017). A novel miniature, wireless neurostimulator in the management of chronic craniofacial pain: Preliminary results from a prospective pilot study. Scandinavian journal of pain, 17, 350-354.

https://doi.org/10.1016/j.sjpain.2017.09.010

113. Van Buyten, J. P., Smet, I., Devos, M., \& Vanquathem, N. E. (2019). High-Frequency Supraorbital Nerve Stimulation With a Novel Wireless Minimally Invasive Device for PostTraumatic Neuralgia: A Case Report. Pain practice : the official journal of World Institute of Pain, 19(4), 435-439. https://doi.org/10.1111/papr.12747

114. Elahi, F., \& Reddy, C. G. (2015). Sphenopalatine ganglion electrical nerve stimulation implant for intractable facial pain. Pain physician, 18(3), E403-E409.

115. Texakalidis, P., Xenos, D., Tora, M. S., Wetzel, J. S., \& Boulis, N. M. (2019). Comparative safety and efficacy of percutaneous approaches for the treatment of trigeminal neuralgia: A systematic review and meta-analysis. Clinical neurology and neurosurgery, 182, 112-122. https://doi.org/10.1016/j.clineuro.2019.05.011

116. Wu, H., Zhou, J., Chen, J., Gu, Y., Shi, L., \& Ni, H. (2019). Therapeutic efficacy and safety of radiofrequency ablation for the treatment of trigeminal neuralgia: a systematic review and metaanalysis. Journal of pain research, 12, 423-441. https://doi.org/10.2147/JPR.S176960

117. Sharma, R., Phalak, M., Katiyar, V., Borkar, S., Kale, S. S., \& Mahapatra, A. K. (2018). Microvascular decompression versus stereotactic radiosurgery as primary treatment modality for trigeminal neuralgia: A systematic review and meta-analysis of prospective comparative trials. Neurology India, 66(3), 688-694. https://doi.org/10.4103/0028-3886.232342

118. Patra, D. P., Savardekar, A. R., Dossani, R. H., Narayan, V., Mohammed, N., \& Nanda, A. (2018). Repeat Gamma Knife radiosurgery versus microvascular decompression following failure 
of GKRS in trigeminal neuralgia: a systematic review and meta-analysis. Journal of neurosurgery, 1-10. Advance online publication. https://doi.org/10.3171/2018.5.JNS18583 119. Xia, L., Zhong, J., Zhu, J., Wang, Y. N., Dou, N. N., Liu, M. X., Visocchi, M., \& Li, S. T. (2014). Effectiveness and safety of microvascular decompression surgery for treatment of trigeminal neuralgia: a systematic review. The Journal of craniofacial surgery, 25(4), 1413-1417. https://doi.org/10.1097/SCS.0000000000000984

120. Shaefer, J. R., Khawaja, S. N., \& Bavia, P. F. (2018). Sex, Gender, and Orofacial Pain. Dental clinics of North America, 62(4), 665-682. https://doi.org/10.1016/j.cden.2018.06.001

121. Nova, C. V., Zakrzewska, J. M., Baker, S. R., \& Riordain, R. N. (2020). Treatment Outcomes in Trigeminal Neuralgia-A Systematic Review of Domains, Dimensions and Measures. World neurosurgery: $X, 6,100070$. https://doi.org/10.1016/j.wnsx.2020.100070

122. Chole, R., Patil, R., Degwekar, S. S., \& Bhowate, R. R. (2007). Drug treatment of trigeminal neuralgia: a systematic review of the literature. Journal of oral and maxillofacial surgery : official journal of the American Association of Oral and Maxillofacial Surgeons, 65(1), 40-45. https://doi.org/10.1016/j.joms.2005.12.063

123. Candido, K. D., Massey, S. T., Sauer, R., Darabad, R. R., \& Knezevic, N. N. (2013). A novel revision to the classical transnasal topical sphenopalatine ganglion block for the treatment of headache and facial pain. Pain physician, 16(6), E769-E778. 